\title{
Leibniz on Intellectual Pleasure, Perception of Perfection, and Power
}

\author{
Saja Parvizian \\ forthcoming Theoria \\ Penultimate Draft
}

\begin{abstract}
Leibniz is unclear about the nature of pleasure. In some texts, he describes pleasure as a perception of perfection, while in other texts he describes pleasure as being caused by a perception of perfection. In this paper, I disambiguate two senses of 'perception of perfection', which clarifies Leibniz's considered position. I argue that pleasure is a perception of an increase in a substance's power which is caused by a substance's knowledge of a perfection of the universe or God. This reading helps clarify the nature of Leibnizian happiness. Happiness is a cognitive process (akin to a mood), constituted fundamentally out of pleasure, which is grounded in increases in a substance's power. A rational substance will sustain its happiness so long as it is more powerful than it is weak, and it is engaging in activities that increase its power.
\end{abstract}

Keywords: Leibniz, ethics, pleasure, happiness, power

\section{Introduction}

According to Leibniz, pleasure (voluptas/plaisir) is fundamental to the happiness [beatitudo/bonheur] of rational substances (see, e.g., GR II: 574; RB: 194, GR II: 579-84/SLT: 167-9), which is one of the perfections of the best of all possible worlds (see, e.g. G IV: 462/AG: 68, L: 279). ${ }^{1}$ But Leibniz does not have in mind any kind of pleasure, but specifically intellectual pleasure. That

\footnotetext{
${ }^{1}$ I employ the following abbreviations for primary texts: 'A': Sämtliche Schriften und Briefe (cited by series, volume and page); 'AG': Philosophical Essays (cited by page); 'E':
} 
is, the kind of pleasure which is (broadly construed) grounded in knowledge. ${ }^{2}$ The nature of Leibnizian happiness is usually treated in the literature in the context of how God selects the best of all possible worlds, and correspondingly how the perfections in this world are maximized. In world-selection, must there be a tradeoff between metaphysical criteria (e.g. simplicity of laws, harmony, diversity of phenomena) and moral criteria (happiness and virtue), or can God maximize all of these perfections? (G IV: 431/AG: 39, A IV: $615 / \mathrm{R}: 105 ; \mathrm{H}: 188) .{ }^{3}$ There are a variety of responses to this question in the literature, ${ }^{4}$ but I want to bracket this issue and address a more

God. Guil. Leibnitii Opera Philosophica (cited by page); 'G': Die philosophischen Schriften von Gottfried Wilhelm Leibniz (cited by volume and page); 'GR': Textes inédits d'après de la bibliothèque provincial de Hanovre (cited by volume and page); 'GW': Briefwechsel zwischen Leibniz und Christian Wolff (cited by page); 'H': Theodicy: Essays on the Goodness of God, the Freedom of Man, and the Origin of Evil (cited by page); 'L': Philosophical Papers and Letters (cited by page); 'M': Rechtphilosophisches aus Leibnizens ungedruckten Schriften (cited by page); 'MP': Philosophical Writings (cited by page); 'R': Political Writings (cited by page); 'RB': New Essays on Human Understanding (cited by page); 'SLT': The Shorter Leibniz Texts (cited by page); 'W': Leibniz Selections (cited by page).

${ }^{2}$ In what follows, it should be assumed that I am always speaking of intellectual pleasure when I speak of 'pleasure', unless I explicitly mention sensory pleasure. Although there is nothing inconsistent with saying that sensory pleasures may contribute to happiness, in general, Leibniz clearly has in mind intellectual pleasure when he speaks of pleasure being constitutive of happiness (see, e.g., RB: 194; H: 282, 297), and to the best of my knowledge, he never claims that sensory pleasures have a role in happiness (GR II: 583/SLT: 170). As Irwin writes, "Perhaps, then, Leibniz really means that happiness consists in pleasure taken in appropriate activities and states" (2008: 316). As we will see below, I argue that these "appropriate activities and states" are epistemic: intellectual pleasure is the kind of pleasure that is (broadly construed) grounded in knowledge. This is the kind of pleasure that Leibniz is mostly talking about when he uses 'pleasure' in an unspecified manner. Sensory pleasure, as I understand it, is not grounded in knowledge. Rather, it is grounded in confused perceptions of changes in the body. Although I am not concerned with the nature of sensory pleasure in this paper, I will briefly discuss it in section 5.1.

${ }^{3}$ While it is clear that Leibniz claims that happiness is a perfection of the best of all possible worlds, it is unclear what kind of perfection it is. Leibniz distinguishes between metaphysical, physical, and moral perfection (H: 258). Strickland claims that happiness corresponds to Leibniz's use of 'physical perfection' (2006: 27). While I will refer to happiness as a perfection, I will not come down on how to categorize this perfection.

${ }^{4}$ There are broadly two camps with respect to this question. First, there are commentators who claim that Leibniz is not concerned at all with the moral criteria (Coutarat 1901: 237, Russell 1937: 199). Second, there are commentators who claim there is no conflict 
fundamental one concerning the nature of happiness.

Leibnizian happiness, in and of itself, has not received a proper analysis, and this is in part due to a lack of attention to the main component of happiness, namely, pleasure. Moreover, when commentators do discuss Leibnizian pleasure (mostly in passing) they are unclear about its nature, and this is in part due to Leibniz's differing descriptions of pleasure. Some commentators claim that pleasure is a perception of perfection. For example, Strickland writes that "the path to happiness starts with a feeling or perception of perfection, and this very feeling is pleasure" (2006: 28). ${ }^{5}$ On this view, pleasure is interpreted as an intentional state. When we experience pleasure we may, for example, be aware of an instance of harmony in the world. Call this the intentionalist reading. Other commentators claim that pleasure is caused by a perception of perfection. For example, Brown writes that pleasure is "an inner feeling that is produced by the perception of the perfection of an object" (2011: 278, emphasis added). ${ }^{6}$ Given that such a reading does not affirm that pleasure is a perception of perfection, it seems that on this view pleasure is a non-intentional mental state. That is, pleasure is a mere feeling in the mind. Call this the qualitative reading. To complicate matters, some commentators slip between describing pleasure in both of these ways. ${ }^{7}$ Prima facie, these readings are inconsistent: Leibnizian pleasure cannot be (wholly) intentional and non-intentional.

In this paper, I reconcile this tension by arguing that pleasure is both a perception of perfection and caused by a perception of perfection. This requires distinguishing two senses of 'perception of perfection'. Though he is often unclear, Leibniz actually alternates between using 'perception of

between the metaphysical and moral criteria (Blumenfeld 1995: 401, Grua 1953: 338-9, Rutherford 1995: 47-9, Strickland 2006: 148).

${ }^{5}$ See also Jorati (2014: 757), Johns (2013: 118), Look (2007: 29), and Youpa (2005: $317)$.

${ }^{6}$ Similarly, Rutherford writes that "the best sort of pleasure is derived through the distinct perception of perfection" (1995: 50).

${ }^{7}$ See, e.g., Brown (2011: 292, 301, cf. 1995: 413). 
perfection' to designate an epistemic perception, that is, an item of knowledge, and using 'perception of perfection' to designate a mere perception, that is, a perceptual state that is intentional, but does not amount to knowledge. I argue that pleasure is a perception of the latter type (a mere perception), caused by a perception of the former type (an epistemic perception). Pleasure arises from knowledge of the perfections of the universe and God, yet it is an intentional state in its own right-it is a perception of a specific kind of perfection.

What perfection, then, is pleasure about? I argue that pleasure consists in a representation of an increase in a substance's power (this is contrasted with pain, which is a representation of a decrease in a substance's power). ${ }^{8}$ That pleasure has power as its object makes sense given Leibniz's views on the systematic relationship between knowledge, activity, power, and pleasure. In the Discourse on Metaphysics $§ 15$, for example, Leibniz tells us that when a rational substance acquires knowledge and thereby increases in power, such increases are accompanied by experiences of pleasure (G IV: 440-1/AG: 48).

This reading of pleasure has the benefit of clarifying Leibnizian happiness in two key respects. First, it helps us understand the cognitive status of happiness. For Leibniz, happiness is a cognitive process (akin to what we would now call a mood). This cognitive process amounts to an enduring state of joy, which consists of a predominance of pleasure over pain. Rational substances are happy when they are, on balance, more powerful than they are weak, and have a stable awareness of their power, and are consistently engaging in activities that increase their power. Second, it helps us understand why

\footnotetext{
${ }^{8}$ Frey comes close to claiming that pleasure is about power: "attainment or the exercise of the perfection of the power is intrinsically pleasing to the agent who possesses the power, and so knowledge is intrinsically pleasing to rational minds" (2016: 617). Frey claims, at the very least, that exercising the perfection of power causes an experience of pleasure, but she does not make the separate claim that pleasure is about or represents the perfection of power. Hostler also approaches my reading, claiming that pleasure is about increasing perfection, but he does not specify the nature of this perfection that is increasing (1975: 23).
} 
Leibniz claims that happiness is a perfection (see, e.g., L: 279). Happiness is a perfection of rational substances because in virtue of being constituted by consistent and stable representations of power (a metaphysical perfection in its own right), happiness by extension acquires the status of a perfection as well.

\section{Preliminaries: The Intentionalist and Qual- itative Readings in Focus}

Before proceeding, an important-and extended-clarification is in order about the reconciliation on offer. There are generally two issues concerning the nature of mental states like pleasure and pain. First, there is the question of the affective nature of pleasure, that is, the way in which pleasure feels to the subject. Often, it is claimed that pleasure has a positive valence, while pain has a negative valence (see, e.g., Bain \& Brady 2014). The affective nature of pleasure is often taken as a datum for any theory of pleasure. ${ }^{9}$ Second, there is a further question of the intentionality of pleasure, i.e. whether pleasure has content. ${ }^{10}$ Does pleasure intrinsically tell us anything about ourselves or environment?

There are broadly three approaches to tackling these two issues. First, one might claim that pleasure is wholly affective, and that it does not have content-it is a mere feeling in the mind (see, e.g., Bramble 2013). This is the qualitative reading above. Second, one might say that pleasure is wholly

\footnotetext{
${ }^{9}$ Leibniz would surely agree that pleasure and pain have affective components, indeed it is hard to read him as talking about pleasure and pain if he did not think they were affective in some way. Of course, however, this is something that he does not discuss explicitly (but again, this could be just because it is an obvious point). Nonetheless, the affective nature of pleasure and pain is suggested by his claims that experiences of pleasure are pleasant or delightful and that experiences of pain involve suffering (RB: 162-8).

${ }^{10} \mathrm{By}$ 'content', I mean intentional content, that is, content that is semantically evaluable. Of course, there is a general sense in which non-intentional qualitative mental properties or states have content, in that there is something phenomenologically given in those states or properties (Montague 2016).
} 
intentional, and that its affective qualities are exhausted by its intentional content (see, e.g., Tye 1995). This is a strong version of the intentionalist reading. Third, one might say that pleasure is a mixed state: it has an affective component that is non-intentional, and a separate intentional component (see, e.g., Block 1995: 269). This is a weak version of the intentionalist reading.

As I understand Leibniz, he cannot accept the qualitative reading, because he claims that the perceptual states of a substance are representational (or so I will argue). However, he is not necessarily committed to the claim that every perceptual state of a substance is wholly representational. With that said, it would seem that both the weak and strong intentionalist readings are technically available to Leibniz. However, as will become clear, the weak intentionalist reading will be eliminated because Leibniz claims that, at least in the case of pleasure, the essence of pleasure consists in its being a perception of perfection. And as I read Leibniz, this is a claim about the essential representationality of pleasure. Thus, I will argue for a strong intentionalist reading of Leibnizian pleasure.

Nonetheless, ascribing strong intentionalism to Leibniz raises some important questions about pleasure and its affective status. Philosophers working on pleasure and pain are often first and foremost concerned with the affective nature of these mental states, even if they go in for a strong intententionalist reading. Thus, one explanatory challenge for a strong intentionalist reading is to explain how the content of pleasure accounts for its affective qualities (see, e.g., Cutter \& Tye 2011, Bain 2003). ${ }^{11}$ Not losing sight of the affective nature of pleasure is important for a variety of reasons. First, the affective nature of pleasure is often connected to its motivational status. Leibniz clearly recognizes that pleasure is a driving force in action-indeed, he is often characterized as a hedonist (see, e.g., L: 136, L: 424). ${ }^{12}$ Second, and relatedly,

\footnotetext{
${ }^{11}$ This is not a problem for the weak intentionalist reading, for a separate non-intentional affective component of pleasure is already being admitted.

${ }^{12}$ For hedonist readings of Leibniz see, e.g, Hostler (1975: 47) and Brown (1995: 413,
} 
one might wonder how pleasure as a representational state is different from other mental states that are not pleasures, yet represent the same property. In the present case, the issue concerns how Leibnizian pleasures are distinctive in the way that they represent power, for surely there are other mental representations of power that are distinct from pleasure.

I think that Leibniz has the resources to meet these explanatory demands, but he clearly does not always approach pleasure with such issues in mind, and thus the texts are underdetermined. For him, the main puzzle is just to explain what pleasure is about and ground that explanation in his broader metaphysical and epistemological system. Correspondingly, that will be my primary interpretive task here. To be clear, I think that a strong intentionalist reading must say something about how the affective nature of pleasure is exhausted by its intentional content. And I will provide an explanation-albeit speculative-about how this might work. However, while a strong intentionalist ought to have a story about these further related questions (e.g. motivation)-it need not provide them immediately to deserve a seat at the table. ${ }^{13}$ While I will briefly develop a view about the affective nature of pleasure, it is beyond the scope of this paper to address these more fine-grained issues in detail, and thus I will generally bracket the relationship between the intentional, affective, and motive aspects of pleasure. But the interpretation developed here will surely lay the groundwork for tackling these issues in future work. ${ }^{14}$

2011). For an argument against the hedonist reading see Frey (2016).

${ }^{13}$ One reason for thinking that Leibniz is doing something novel in his analysis of pleasure is that he is departing from a qualitative reading of sensations and emotions that was, arguably, dominant in the early modern period. Indeed, commentators have often claimed that the Cartesians were qualia realists, who did not view sensations and emotions as having any content. To be sure, it is unclear whether Leibniz interpreted the Cartesians in this way, but that is besides the point. For qualia realist readings of the Cartesians see MacKenzie (1990), Field (1993), and Cunning (2006). For intentionalist readings see De Rosa (2007), Gottlieb \& Parvizian (2018), and Simmons (1999).

${ }^{14}$ Going forward, I will drop the qualification of 'strong' when referring to the intentionalist reading I am developing-unless specifying so is required for clarity. 


\section{Two Senses of 'Perception of Perfection'}

\subsection{Conflicting Texts}

Admittedly, the texts seem unclear about the nature of pleasure. In support of the intentionalist reading, one could cite texts such as the following: "pleasure consists in the perception of perfection [perceptione perfectionis]" (MP: 147/G VII: 291); "pleasure is the feeling of a perfection or an excellence [die Empfindung einer Vollkommenheit oder Vortrefflichkeit]" (G VII: 86/L: 425); "pleasure. . is nothing other than the feeling of some perfection" (W: 567); "pleasure is the sensation of perfection [sensus perfectionis]" (AG: 233/GW: 172); and pleasure is "nothing other than a sense of perfection [sensum perfectionis]" (GW: 18). ${ }^{15}$

In support of the qualitative reading, one could cite texts such as the following: pleasure "is permanent and cannot deceive, nor can it cause a future unhappiness if it arises from knowledge" (G VII: 88/L: 426); and "pleasure is the feeling of some perfection, and this perfection which causes pleasure can be found not only in ourselves, but also elsewhere" (GR II: 579/SLT: 169). The latter text used in support of the qualitative reading is particularly noteworthy. Leibniz starts off with seemingly intentionalist language: "pleasure is the feeling of some perfection". However, he then seems to indicate that a causal (not intentional) relationship holds between pleasure and perfection: "this perfection which causes pleasure." Since a perfection cannot immediately cause a pleasure given Leibniz's denial of genuine intersubstantial causation (Monadology $\S 7$, G VI: 607/AG: 213-4), it is natural to read Leibniz as claiming that a perception of perfection mediately causes pleasure, which should then be understood as a mere feeling, i.e. a nonintentional state.

Undoubtedly, there is a causal story to be told about how pleasures are

\footnotetext{
${ }^{15}$ Letter to Christian Wolff 21 February 1705, Translated by Strickland (http://www.leibniz-translations.com/wolff.htm).
} 
generated, but I think we have every reason to be suspicious of a qualitative reading right off the bat. One of the essential features of substances, particularly rational substances, is that their perceptual states express - i.e. represent - other substances and the universe. As Leibniz tells us in the Monadology (1714), "each simple substance is a perpetual, living mirror of the universe" (G VI: 616/AG: 220) and "the nature of the monad is representative [représentative]" (G VI: 617/AG: 220; see also G IV: 434/AG: 42, G VI: 598/AG: 207, G VI: 604/AG: 211). Leibniz has a distinctive theory of representation or expression, and for present purposes, we need not delve into the details of that theory. ${ }^{16}$ All we need to know is that, for Leibniz, perceptions have representational content, and at the very least, we can say that perceptions represent some feature of the universe or God. Thus, we should try to work out some type of intentionalist reading.

One might try to push back on the representationalist reading of pleasure, by arguing that pleasures are appetites, not perceptions. As is wellknown, Leibniz divides the mental states of a monad into appetites and perceptions. ${ }^{17}$ While it seems clear that perceptions are representational, it is unclear whether appetites-the strivings toward other perceptions-must be representational as well (Simmons 2001: 41-2, fn. 19). However, the problem with this move should be clear: Leibniz, in much of the texts we will consider, consistently describes pleasure as a perception. Indeed, nowhere does he claim or imply that pleasure is an appetite. Moreover, as we will see later, Leibniz clearly claims that the essence of pleasure consists in its being a perception of perfection. Thus, much work needs to be done to re-read Leibniz's claim that pleasure is a perception of perfection, as the claim that pleasure is (say) an appetite for perfection.

The interpretive challenge before us, then, is to provide an intentionalist

\footnotetext{
${ }^{16}$ For discussions of Leibniz's theory of representation see Adams (1994: 222-3), Duncan (2015), McRae (1976: 20-26), Rescher (1967: 61-3), Rutherford (1995: 38-9), Simmons (2001), and Wilson (1992).

${ }^{17}$ For in depth discussion of Leibnizian appetites see Jorati (2018) and Lee (2014).
} 
reading that can explain two Leibnizian commitments concerning the nature of pleasure:

1. Pleasure is a perception of perfection.

2. Pleasure is caused by a perception of perfection.

I believe that Leibniz has the resources to answer this challenge. Before considering my proposed solution, however, it will be instructive to consider an intentionalist reading of pleasure that is akin to the one I will offer, but one that I want to reject.

\subsection{The Epistemic Reading}

On an epistemic reading, in claiming that intellectual pleasure is a perception of perfection, Leibniz is really saying that pleasure consists in knowledge of perfection. For example, Andrew Youpa writes that "pleasure is the sense perception or knowledge of perfection" (2005: 317, see also 2016). It is clear that Youpa must have intellectual pleasure in mind, given that he identifies pleasure with a kind of knowledge.

The epistemic reading is not unmotivated. Leibniz clearly indicates a close connection between the acquisition of knowledge and pleasure, and he also appeals to knowledge in order to distinguish intellectual pleasure, the type of pleasure that can be constitutive of genuine happiness, from sensory pleasure, the type of pleasure that not only cannot be constitutive of genuine happiness but is often a barrier to it (GR II: 579-80/SLT: 170). Furthermore, this reading can meet our interpretive challenge. If one stipulates that the use of 'perception of perfection' in the context of descriptions of pleasure is synonymous with 'knowledge', one could say that pleasure is a kind of knowledge that is caused by other perceptions of perfection. So, it seems that the epistemic reading has a lot going for it. 
But what exactly is the epistemic reading claiming in saying that "pleasure is knowledge"? Let us disambiguate three readings of this view. The first two readings-based on the is of predication-are:

$\mathbf{E R}_{1}$ : Every instance of pleasure is an instance of knowledge of perfection.

$\mathbf{E R}_{2}$ : Every instance of knowledge of perfection is pleasurable. ${ }^{18}$

The third reading-based on the is of identity-is:

$\mathbf{E R}_{3}$ : Every instance of pleasure is an instance of knowledge of perfection and every instance of knowledge of perfection is an instance of pleasure.

The real epistemic readings of pleasure are $\mathrm{ER}_{1}$ and $\mathrm{ER}_{3} . \mathrm{ER}_{2}$ is not truly an epistemic reading, but it is worth considering here as it will help clarify my considered view on the relationship between knowledge and pleasure. I will provide brief arguments against all three readings. It should be noted, however, that if $\mathrm{ER}_{1}$ is false, then a fortiori $\mathrm{ER}_{3}$ is false as well.

Regarding $\mathrm{ER}_{1}$ : as a sensible quality ${ }^{19}$ pleasure is simply not the type of mental state that could count as knowledge. ${ }^{20}$ In Meditations on Knowledge, Truth, and Ideas (1684) Leibniz offers us a sketch of his epistemology. Leibniz distinguishes different grades of knowledge (cognitio), and it is clear from his descriptions of these different grades of knowledge that knowledge

\footnotetext{
${ }^{18} \mathrm{ER}_{2}$ is distinct from the claim that the pursuit of knowledge is pleasurable. The pursuit of knowledge might not be successful, as one could fail to achieve knowledge, which is why I am not concerned with this view as a real iteration of the epistemic reading.

${ }^{19}$ The claim that pleasure is a sensible quality is merely the claim that pleasure is simple in that we cannot analyze it-through itself-into discrete requirements (Adams 1994: 120).

${ }^{20}$ There is a more direct argument that can be made to this effect, but which cannot be placed on the table just yet. Pleasure is a mere perception, that is, an expressive or representational state, but such perceptions in and of themselves are not items of knowledge. As McRae points out, "Leibniz makes it clear that he does not equate expressing with thinking or knowing" (1976: 20).
} 
involves ideas, notions, or concepts (Leibniz alternates between these terms in this text). For example, Leibniz writes: "When everything that enters into a distinct notion [notitiam distinctam] is, again, distinctly known, or when analysis has been carried to completion, then knowledge is adequate" (G IV: 423/AG: 24). In short, while one can have some grade of knowledge about an instance of pleasure e.g. through a distinct notion of that pleasure ${ }^{21}$-the pleasure itself cannot be an item of knowledge. ${ }^{22}$

Regarding $\mathrm{ER}_{3}$ : Leibniz draws a clear metaphysical distinction between knowledge of perfection and pleasure. Here, I want to consider one important text. In the Principles of Nature and Grace (1714), Leibniz says the following about the beatific vision:

For the love of God also fulfills our hopes, and leads us down the road of supreme happiness [bonheur], because by virtue of the perfect order established in the universe, everything is done in the best possible way, both for the general good and for the greatest individual good of those who are convinced of this, and who are content with divine government, which cannot fail to be found in those who know how to love the source of all good. It is true that supreme felicity [felicité] (with whatever beatific vision or knowledge of God it may be accompanied [accompagnée]) can never be complete, because, since God is infinite, he can never be entirely known. (G VI: 606/AG: 213)

If $\mathrm{ER}_{3}$ were correct, then surely Leibniz would claim that the beatific vision, i.e. unmediated knowledge of the perfections of God, is an instance of pleasure. Indeed, the beatific vision would be a prime candidate for $\mathrm{ER}_{3}$. However, we see here that Leibniz implies a distinction between the beatific

\footnotetext{
${ }^{21}$ That we can have a distinct notion of pleasure follows from Leibniz's claim that we have a real definition of pleasure-see section 3.4 below.

${ }^{22}$ For more on Leibniz's epistemology, see McRae (1995).
} 
vision and the supreme felicity that accompanies it. Though the beatific vision might always be accompanied by pleasure and happiness, there remains a strict distinction between these two mental states (see also H: 297). ${ }^{23}$

Regarding $\mathrm{ER}_{2}$ : I read $\mathrm{ER}_{2}$ as the claim that pleasure and knowledge are distinct (it does not presuppose $\mathrm{ER}_{1}$ or $\mathrm{ER}_{3}$ ), but knowledge of perfection is pleasurable because it is always accompanied by pleasure (a distinct mental state). It might have seemed that I was implicitly affirming $\mathrm{ER}_{2}$ in my response to $\mathrm{ER}_{3}$-but this is not the case.

The reason for rejecting $\mathrm{ER}_{2}$ is that Leibniz allows for the possibility of a rational substance to have knowledge of perfection yet not experience any accompanying pleasure. This is because, for Leibniz, in order for pleasure to be sustained in a rational substance such that it can contribute to happiness, the rational substance must be making epistemic progress. I would like to distinguish two kinds of epistemic progress in Leibniz's system. First, there is epistemic progress when a rational substance acquires new knowledge. The texts generally have this kind of epistemic progress in mind. For example, Leibniz writes:

Thus our happiness [bonheur] will never consist, and must never consist, in complete joy, in which nothing is left to desire, and which would dull our mind, but must consist in a perpetual progress (progrès perpétuel) to new pleasures and new perfections. (G VI: 606/AG: 213; see also RB: 194)

The thought here is that happiness is, in some sense, grounded in a progres-

\footnotetext{
${ }^{23}$ The beatific vision might be a special case of knowledge that is always accompanied by pleasure. As Leibniz writes in the Principles of Nature and Grace: "Since God is the most perfect and happiest, and consequently, the substance most worthy of love, and since genuinely pure love consists in the state that allows one to take pleasure in the perfections and felicity of the beloved, this love must give us the greatest pleasure of which we are capable whenever God is its object" (G VI: 605/AG: 212, see also SLT: 161). This is not a counterexample to my argument against $\mathrm{ER}_{2}$ below, however, because it is still not the case that every instance of knowledge of perfection is accompanied by an experience of pleasure.
} 
sion of pleasures. And supposing that pleasure is grounded, in some sense, in knowledge of perfection, if we cease to acquire new knowledge, then we will cease to acquire new pleasures (and thus our happiness will be compromised). This first kind of epistemic progress seems to imply that unless an item of knowledge is novel, then it will not be productive of pleasure. Call this strong epistemic progress.

Given Leibniz's commitment to strong epistemic progress, one might think that the objection to $\mathrm{ER}_{2}$ is that common or familiar knowledge will not be accompanied by pleasure. However, this is not the case. For surely, a rational substance can reflect on their current body of knowledge or apply previously acquired knowledge to further matters, and still experience pleasure. For example, consider the advanced theologian who reflects on their knowledge of the attributes of God. They may not be refining their knowledge of the attributes at all, nonetheless, such reflection does involve a kind of epistemic progress, and thus that knowledge will still be productive of pleasure. Call this weak epistemic progress.

Through distinguishing strong and weak epistemic progress (both of which are consistent and not mutually exclusive), we can now unveil the real objection to $\mathrm{ER}_{2}$. In both strong and weak epistemic progress, the knowledge that is productive of pleasure is always conscious knowledge. In the case of strong epistemic progress, knowledge of perfection is pleasurable because we have just acquired it (and are thus conscious of it), and in the case of weak epistemic progress, knowledge of perfection is pleasurable because we are occurrently reflecting on it. This suggests that if we truly "dull our mind", that is, no longer consciously engage our knowledge, then that knowledge will no longer be productive of pleasure. Consider the theologian who spends ten years of his life learning about the attributes of God, but then abandons his theological studies to pursue some other affairs, and never considers the attributes of God again. Surely, we would say that this theologian still has knowledge of God. Indeed, if prompted, he might be able to produce an on- 
tological argument for God's existence. But insofar as his knowledge is now dormant, it will not be a source for renewing pleasure and sustaining happiness. In short, I am saying that Leibniz rejects $\mathrm{ER}_{2}$ because he is committed to the claim that Conscious Knowledge is Pleasurable:

CP: Every (conscious) instance of knowledge of perfection is pleasurable.

But again, to accept this claim does not entail that pleasure $i s$ knowledge.

\subsection{The Dual Perception of Perfection Reading}

So, the epistemic reading is not viable. How, then, can we meet our interpretive challenge and reconcile the allegedly conflicting texts? I think that the tension is generated by confusion over what Leibniz means by phrases such as 'perception of perfection', 'feeling of perfection', and so on. I suggest that we disambiguate two senses of 'perception of perfection'. In some instances, Leibniz uses 'perception of perfection' to indicate a perception that amounts to knowledge. For short, let us call these perceptions epistemic perceptions. In other instances, however, Leibniz uses 'perception of perfection' to indicate a perception of perfection that is intentional, but does not amount to knowledge. For short, let us call these (conscious) perceptions mere perceptions. ${ }^{24} \mathrm{I}$ argue that, pleasure consists in a representation of an increase in a

\footnotetext{
${ }^{24}$ Another clarification is in order about my use of the term 'pleasure'. Leibniz draws a distinction between 'semi-pleasures [demi-plaisir]' and 'a whole, genuine pleasure [un plaisir entier et véritable]'. Semi-pleasures are unconscious "minute perceptions" which when accumulated become a conscious genuine pleasure (RB: 165). While I think it is clear that genuine pleasures are intentional and have an affective felt quality, it is less clear whether semi-pleasures are intentional or have an affective felt-quality. In what follows, I am concerned only with conscious or genuine pleasures, and will not address the transformation of semi-pleasures (possibly non-intentional and not affective) into genuine pleasures. With that said, in explaining the connections and transformation between semipleasures and genuine pleasures, one must respect Leibniz's commitment to the Principle of Continuity. For an analysis of how the Principle of Continuity relates to perceptions see Jorgensen (2009).
} 
substance's power (this is contrasted with pain, which is a representation of a decrease in a substance's power). Drawing from a variety of texts, ${ }^{25}$ I argue that pleasure is a mere perception caused by an epistemic perception. That is, pleasure arises from knowledge of the perfections of the universe and God, yet it is also an (intentional) perceptual state. Call this the dual perception of perfection reading.

An important clarification about my critique of the epistemic reading is in order. My problem with the epistemic reading is not with its implicit claim that a perception of perfection can be understood as an instance of knowledge. ${ }^{26}$ Rather my gripe is with the claim that pleasure qua perception of per-

\footnotetext{
${ }^{25}$ I will help myself to a methodological assumption in this paper, namely, that Leibniz has a philosophical system and is thus a systematic philosopher (Whipple 2015). Unlike developmental or modular interpretations of Leibniz (Garber 2014), which argue that Leibniz is merely testing out and developing different theories, I maintain that Leibniz does have settled philosophical positions-at least on the central issues-and these positions are interconnected with one another. And I take it that the nature of happiness-and consequently pleasure-is a central issue in Leibniz's philosophy, and that it would be unacceptable to pin him with having an unclear-let alone inconsistent-account of pleasure and happiness. Nonetheless, as interpreters of Leibniz are all too familiar with, one can find a variety of inconsistent passages in Leibniz on any given philosophical issue. I will note conflicting passages when relevant, however, my aim is to present what I take Leibniz's considered position on pleasure to be, and I will not provide reconciliations for every conflicting passage. For an account of systematic philosophy that I am sympathetic to, see Nelson (2013).

${ }^{26}$ Admittedly, one might naturally think that Leibniz is being sloppy in claiming that knowledge could be a property of a perception, given that when he is careful he claims that knowledge is a property of ideas, notions, or concepts. We need to distinguish two issues here. First, there is the question of whether a perception of perfection (excluding pleasure since it is a sensible quality) can be characterized as an instance of knowledge. Second, there is the question of whether pleasure is, in any sense, caused by a mere perception of perfection. On the first issue: I think this is open to interpretation. While there are texts that one could use to argue against this view, there are texts where Lebniz can be read as claiming that knowledge can be a property (of at least some kinds) of perceptions. For example, Leibniz writes in the Principles of Nature and Grace: "the soul itself knows the things it perceives only so far as it has distinct and heightened perceptions [perceptiones distinctes et reveleées]" (G VI: 605/AG: 211). But given that Leibniz claims that pleasure must be immediately caused by knowledge of perfection, it is reasonable to reconcile the conflicting texts by claiming that when he says pleasure must be caused by a perception of perfection, he means knowledge of perfection. On the second issue: suppose one wants to deny that knowledge can be a property of perception, yet still concede that pleasure
} 
fection is always an instance of knowledge ${ }^{27}$ On my view, pleasure is a mere perception of perfection-a representational state-which in the right kind of circumstances arises from knowledge. But this does not entail a commitment to $\mathrm{ER}_{2}$, for my contention is that, in the right circumstances, knowledge of perfection is pleasurable. As indicated above, there are important exceptions to $\mathrm{ER}_{2}$ that we must acknowledge to understand Leibnizian happiness.

There are a variety of texts which suggest the dual perception of perfection reading. Admittedly, however, they are not all knock-down texts. Here, I just want to consider several texts that demonstrate the link between knowledge of perfection and pleasure. Let us start by considering the following passages:

It is one of the eternal laws of nature that we shall enjoy the perfection of things and the pleasure which results from it, only in the measure of our knowledge, our good will, and our contribution to this perfection. (G VII: 89/L: 427)

[pleasure] is lasting and cannot deceive, nor give rise to a future sorrow, as long as it derives from knowledge and brings with it a light from which results an inclination to good in the will, that is, virtue. (G VII: 88/L: 426)

We must not distrust the pleasures that arise from intelligence or reasons, when we penetrate the reason of the reason of perfections, that is to say, when we see them follow from their source, which is the absolutely perfect being. (GR II: 580/SLT: 168)

In all of these passages Leibniz claims-amongst other things-that pleasure is somehow grounded in knowledge of perfection. This suggests that when

must be caused by knowledge of perfection. Still one cannot deny the claim that, in a general sense, pleasure is distally caused by a mere perception of perfection. For one does not immediately acquire knowledge of a perfection, rather knowledge of a perfection in part derives from mere perceptions of a perfection. As such, I think for the present task at hand, this worry is a non-starter.

${ }^{27}$ Again, part of the reason for this is the kind of mental state that pleasure is, i.e. a sensible quality. 
Leibniz claims that pleasure is caused by a perception of perfection, he is implying that pleasure is caused by knowledge of perfection.

Now consider the following extended text from Happiness (La Felicité ca. 1694):

Pleasure is the feeling of some perfection [le sentiment de quelque perfection], and this perfection that causes [cause] pleasure can be found not only in us, but also elsewhere. For when we notice it, this very knowledge [conaissance] excites some perfection in us, because the representation of the perfection is also a perfection [parce que la representation de la perfection en est une aussi]. This is why it is good to familiarize oneself with objects that have many perfections. And we must avoid the hate and envy which prevents us from taking pleasure in these objects. (GR II: 579/SLT: 169, see also RB: 194)

Leibniz, in my view, is a bit unclear here. But this passage (from hereon the 'pleasure/knowledge passage') is very insightful once read carefully. Leibniz begins by claiming that pleasure is the "feeling of some perfection." Next, he claims that the perfection that causes pleasure can be instantiated in a variety of places-in us and in the universe. But then, Leibniz makes an important clarification to this statement: perfection does not immediately cause pleasure, rather, it does so mediately through knowledge: "for when we notice it [the perfection], this very knowledge excites some further perfection in us." This clarification is key, for it shows that it is knowledge of perfection that gives rise to the feeling or perception of perfection (pleasure).

Notice that Leibniz is also unclear about what pleasure represents. He seems to leave it open, allowing for pleasure to represent a multitude of different kinds of perfections. This is because Leibniz suggests that pleasure is about the same perfection that the knowledge which gives rise to it is about. Given that we can have knowledge of any kind of perfection, Leibniz 
seems to commit himself to the view that pleasure can be about a DivERSITY of Perfections:

DP: If the knowledge that gives rise to some pleasure is about (any) perfection $x$, then the pleasure that arises from that knowledge will also be about perfection $x$.

It seems that other intentionalist readings of Leibnizian pleasure are committed to Diversity of Perfections, as they implicitly leave open the possibility that pleasure can be about any perfection. In general, I think this is problematic - at least on a strong intentionalist reading - because it is unclear what would unite token pleasures as being the same type of mental state given that their essential nature on this view is exhausted by their representational content. If pleasure can be about any type of perfection, what makes a pleasure about perfection $x$, the same kind of thing as a pleasure about perfection $y$ ?

But Diversity of Perfections is something Leibniz cannot abide, for in other texts, he claims (or so I will argue) that the object of pleasure is always the perfection of power. That is, Leibniz is actually committed to the claim that pleasure is always about a Singular Perfection:

SP: While the knowledge that (can) give rise to pleasure may be about (any) perfection $x$, the pleasure that arises from this knowledge of $x$ is always about the perfection of power, $p$.

One final note about the pleasure/knowledge passage. Leibniz reveals a commitment to a principle concerning the nature of perfection that will prove useful in illustrating his commitment to (1) the representationality of pleasure and (2) why the representational nature of pleasure renders both pleasure and happiness perfections of the mind. I will call this the principle of Representational Perfection: 
RP: If a mental state, $M$, accurately represents some perfection, $P$, then $M$ is a perfection as well. ${ }^{28}$

Leibniz is clearly committed to the principle of Representational PerFECTION ${ }^{29}$ and explicitly applies it to pleasure in the pleasure/knowledge passage: "the representation of the perfection is also a perfection". The context of the pleasure/knowledge passage reveals that 'representation of perfection' refers to pleasure, and thus Leibniz is claiming that pleasure is a perfection as well. Notice that this text implies that Leibniz does think that pleasure is intentional, and he commits himself to the further claim that pleasure is a perfection of its own kind because of this. ${ }^{30}$

\subsection{Strong Intentionalism}

Let us now turn to the evidence for a strong intentionalist reading of pleasure. The principle of Representational Perfection clearly commits Leibniz to the claim that pleasure is intentional, but it does not commit him to the claim that pleasure is wholly intentional. As such, the weak intentionalist reading is still an option. Here, I want to consider a key text that tips the scale in favor of a strong intentionalist reading. In a letter to Christian Wolff (1705), Leibniz writes:

We are not able to give a nominal definition of pleasure (voluptatis), and pleasantness (suavitas) is no more familiar than plea-

\footnotetext{
${ }^{28}$ The qualification of accuracy is crucial because it will in part explain why sensory pleasures do not count as a perfection. As I will argue below (section 5.1), sensory pleasures are a misrepresentation of an increase in power. As such, sensory pleasures are not about a perfection at all, and thus cannot count as a representational perfection.

${ }^{29} \mathrm{It}$ is beyond the scope of this paper to offer a full explanation of the principle of REPResentational Perfection. But I believe that Leibniz's broader metaphysical commitments provide grounds for this principle. See Mercer's discussion of "emanative harmony" as a grounds for the principle of RePRESENTATIONAL PERfECTION (2001: 209-217).

${ }^{30} \mathrm{My}$ claim here is that insofar as pleasure is a representation of the perfection of power, it does not follow from the principle of Representational Perfection that pleasure is another instance of the perfection of power as well. Rather, pleasure is a perfection of its own kind (I will leave open what that is for the purposes of this paper).
} 
sure (voluptas); yet pleasure admits of a real definition, and I think it is nothing other than a sense of perfection (sensum perfectionis $).(\mathrm{GW}: 18)^{31}$

To unpack this passage, we need to say something about Leibniz's theory of definitions (Puryear 2012: 235-40). According to Leibniz, a nominal definition of $x$ identifies some set of external or distinguishing features of $x$ such that one could recognize $x$ upon first encountering $x$. However, a nominal definition of $x$ does not identify the essence of $x$. For example, specifying that gold is heavy, yellow, and insoluble in aqua fortis would serve as a nominal definition of gold, but such distinguishing features do not capture the essence of gold. A real definition, on the other hand, would identify the essence of $x$ and thereby establish its possibility. For example, Leibniz writes:

The concept of a circle set up by Euclid, that of a figure described by the motion of a straight line in a plane about a fixed end, affords a real definition, for such a figure is evidently possible. (L: 230)

In claiming that a nominal definition of pleasure does not exist, Leibniz is implying that one could not identify pleasure without having experienced it. Nonetheless, we can give a real definition of pleasure, namely, that it consists in a perception of perfection. Still, even if one knows the real definition of pleasure, one would still not know what it is like to experience pleasure. There is much to say about why we cannot have a nominal definition of pleasure, ${ }^{32}$

\footnotetext{
${ }^{31}$ Translation from Strickland (http://www.leibniz-translations.com/wolff.htm). Similarly, Leibniz writes in the New Essays: "although pleasure cannot be given a nominal definition, and more than light or heat can, it can like them be defined causally" (RB: 194). A causal definition, according to Leibniz, is just a kind of real definition (Puryear 2012: 236).

${ }^{32}$ Again, this goes back to the point made in Section 2 about the affective status of pleasure on a strong intentionalist reading. Perhaps it is the affective nature of pleasure that prevents us from providing a nominal definition-one cannot know what it is like to experience pleasure until one experiences it.
} 
but the upshot for present purposes is that Leibniz is claiming that pleasure is essentially a representational state-that is, a representation of perfection. As such, Leibniz is committed to a strong intentionalist account of pleasure. And I will maintain this going forward.

Having established that Leibniz is a strong intentionalist, we need to say something about the affective nature of pleasure. Recall, according to strong intentionalism, the affective qualities of pleasure are exhausted by the content of pleasure. I do not think that there is any direct textual evidence to settle this matter. Nonetheless, I think that Leibniz has the resources to offer an explanation along the lines given by contemporary intentionalists.

Allow me to briefly speculate about how this could work. A standard move for the strong intentionalist is to claim that whatever property pleasure represents, it represents that property as good (a positive valuational property). Similarly, whatever property pain represents (say, tissue damage) it represents that property as bad (a negative valuational property). As Tye writes: "To experience tissue damage as bad is to undergo an experience which represents that damage as bad" (2008: 34; cf. Cutter \& Tye 2011). Representing the objects of pleasure and pain as having such valuational properties, explains why pleasure has a positive valence and pain has a negative valence.

On this kind of model, then, we need a story about how, whatever properties Leibnizian pleasure and pain do represent, they represent those properties as good or bad (respectively). One could simply say just that: whatever Leibnizian pleasure and pain represent, they represent that property as good or bad (respectively). However, I think that there is a more Leibnizian answer in the vicinity. On the view that I will develop in the next section, pleasure represents an increase in a substance's power, and pain represents a decrease in a substance's power. Leibniz also describes this as a representation of perfection, and a representation of imperfection. Although I will have some brief remarks about perfection and imperfection in the next section, it is beyond 
the scope of this paper to delve into this difficult topic. Nonetheless, I will say this: it is plausible that perfection and imperfection are valuational properties in addition to being strict metaphysical properties in Leibniz's metaphysics. Indeed, Leibniz often talks about "the good which is purely metaphysical" (H: 258). As Youpa writes:

In reuniting goodness and reality, or to what he interchangeably refers to as perfection, Leibniz thus characteristically recovers and attempts to restore a doctrine that had currency among medieval thinkers. (2016)

The upshot is that it is not far-fetched to attribute to Leibniz the following claims that could explain the affective nature of pleasure and pain:

1. Pleasure represents an increase in power as a perfection.

2. Pain represents a decrease in power as an imperfection.

Again, the details here are tricky, and by no means am I claiming that this is the best view, all things considered. But in terms of offering some kind of relevant explanation, Leibniz has the requisite resources.

\section{Pleasure, Perfection, and Power}

Let us now turn, then, to a detailed analysis of the intentionality of pleasure (setting aside, from hereon out, the affective nature of pleasure). What perfection is pleasure about? I will argue that pleasure always represents an increase in a substance's power. As such, Leibniz is committed to Singular Perfection, not Diversity of Perfections.

Leibniz often claims that pleasure represents power, and I too will speak this way for convenience. However, the claim that pleasure represents power is actually just shorthand for the claim that pleasure represents an increase 
in a substance's power. But this is a substantive substitution, and I will give an argument for why we should read the claim that pleasure represents power as the claim that pleasure represents an increase in a substance's power.

Let us start with a couple texts that, at the very least, suggest that pleasure represents power. For example, In On Wisdom (ca. 1690) Leibniz writes:

Perfection shows itself in great freedom and power of action, since all being consists in a kind of power; and the greater the power, the higher and freer the being. (G VII: 87/L: 426)

If pleasure is a perception of perfection, and perfection "shows itself in great freedom and power of action," then it is reasonable to claim that a perception of perfection is a representation of power. Regarding joy and pleasure more specifically, Leibniz writes that joy,

which a person can always create for himself when his mind is sound, consists in the feeling of pleasure in himself and in the powers of his mind. (G VII: 89/L: 427; see also L: 136-7)

Let us look at a more definitive text. In a 1677 letter to Arnold Eckhard, Leibniz claims that pleasure consists in "consciousness of power." Leibniz's correspondence with Eckhard concerns whether simple sensible qualities can be counted among the divine perfections. In this context, Leibniz turns to the nature of pleasure and pain:

There is more perfection or reality in a mind which suffers than in an indifferent one which is neither enjoying nor suffering, so that in a metaphysical sense, pain too is a perfection. But since pleasure is also a metaphysical perfection [voluptas est etiam perfectio metaphysica], it seems that we must ask whether pain or pleasure is the greater perfection, metaphysically speaking. It seems that 
pleasure is the greater perfection, because it is the consciousness of power [conscientia potentiae], while pain is the consciousness of powerlessness conscientia imbecillitatis]. But powerlessness, again speaking metaphysically, is an imperfection [imperfectio], and the consciousness of metaphysical imperfection is less perfect, again speaking metaphysically, than the consciousness of metaphysical perfection. So pain implies a certain imperfection in the suffering subject. (G I: 266/L: 177) ${ }^{33}$

Leibniz's comparison of the metaphysical status of pleasure and pain should be read against the backdrop of the principle of REPRESENTATIONAL PERFECTION. Recall, this principle states that: if a mental state, $M$, accurately represents some perfection, $P$, then $M$ is a perfection as well. The reason why pleasure is a metaphysical perfection is because pleasure consists in "consciousenss of power" or in more precise terms given Leibniz's representationalism, a representation of power. Power is a perfection of substances, and qua perfection it consists in a certain "degree or quantity of reality or essence" as indicated earlier in the letter (Ibid.). The reason why pain is "less perfect" than pleasure is because pain consists in "consciousness of powerlessness", that is, a representation of powerlessness (or weakness). Powerlessness is an imperfection: it does not indicate a degree of reality or essence. As such,

\footnotetext{
${ }^{33}$ There is one text (ca. 1683) where Leibniz seems to contradict the claim that pleasure represents power. In a note on Descartes' Passions of the Soul Leibniz writes: "Descartes thinks that the cause of pleasure consists in the feeling of our powers, provided of course that we realize that we strongly resist something making an attack on us. I think that is only a corollary. For generally, everything that assists an action or performance brings about pleasure, but assistance is chiefly perceived in danger, because then it is perceived more exquisitely. And, if every pleasure consists solely in the knowledge of our strength, not only would beasts not feel pleasure, which Descartes would concede, but neither would we perceive the signs of pleasure in them" (A VI 4: 1488-9, translated by Strickland http://www.leibniz-translations.com/pleasure.htm). This text appears later than the letter to Eckhard, which would suggest that this is Leibniz's considered view. However, the claim that pleasure represents power is also expressed in later texts as well-e.g. the Discourse (1686)-which suggests that Leibniz did not abandon this position.
} 
pain reveals a metaphysical imperfection in the suffering subject. ${ }^{34}$

This is one of the clearest texts where Leibniz claims that pleasure represents power. But notice that he does not claim that pleasure represents an increase in a substance's power. ${ }^{35}$ Why should we read him as implying this more specific claim? There are two main reasons for this reading: direct textual evidence, and broader systematic considerations.

There are two types of texts that help us see that Leibniz's considered view is that pleasure represents an increase in power. First, there are texts that claim that perfection itself consists in an increase or improvement in reality or being. For example, Leibniz writes: "I call any elevation [Erhöhung] of being [des Wesens] a perfection [Vollkommenheit]" (G VII: 87/L: 426). Second, Leibniz explicitly claims that "pleasure is the awareness of increasing perfection" (M: 88). ${ }^{36}$ Taking all the texts considered together, I think the best reading is that pleasure represents an increase in a substance's power.

Before turning to deeper systematic considerations in favor of this view, let us briefly pause to consider what it means for a substance to increase in power. Leibniz examines power in a range of texts, and by no means do I want to offer a definitive view of Leibnizian power and its metaphysical

\footnotetext{
${ }^{34}$ It is interesting, however, that Leibniz concedes that pain, in a certain sense, does involve perfection, because a mind that is suffering has more perfection than one that is indifferent. I do not think that this claim is in real tension with the principle of REPResentational Perfection. Broadly put, I think we could say the following: insofar as pain is a perception, it contributes to the overall degree of reality of a mind (for a perception has some degree of reality), at least quantitatively. But qualitatively speaking, it is not a perfection in the same sense as pleasure, for it is not tracking the power of the substance.

${ }^{35}$ There is an important clarification here: pleasure represents an increase in a rational substance's own power. However, I am not thereby implying that pleasure cannot be distally caused by an increase in another substance's power. I think Leibniz's considered view (and I cannot flesh that out here), is that a substance $x$ can increase in power (and experience pleasure) through acquiring knowledge of another substance $y$ 's increase in power and experience of pleasure. These metaphysical, epistemic, and ethical relationships are crucial for Leibniz's theories of love and moral progress (see, e.g., RB: 163; GR II: 579/R: 83).

${ }^{36}$ Translated by Hostler (1975: 23).
} 
status within a Leibnizian substance. ${ }^{37}$ Instead, I would like to provide a general framework for understanding power, so that we can have a better sense of exactly what pleasure represents. Here, I will focus primarily on the discussion of power in the New Essays, for there the discussion of power is situated within a broader discussion of ethics.

In Chapter xxi, Leibniz writes that "power [potentia/la puissance] in general, then, can be described as the possibility of change" (RB: 169). But change requires actualization of power. So when this possibility is actualized, we can distinguish between active power and passive power. Active power consists in a substance-albeit ideally-causing change in another substance. Passive power consists in a substance (the patient) undergoing change-albeit ideally-due to the actions of another substance (the agent). As such, one can think of active power as a "faculty" and passive power as a "capacity" (RB: 169). For example, a teacher has the faculty of imparting knowledge, and a student has the capacity of learning. However, while the student's mind (the dominant monad) is passive in some respects (perhaps corresponding to the ways in which her organs are being affected by the actions of the teacher), it is also becoming active as it acquires knowledge. She is now in a position to act in the world in new ways given her newfound knowledge. On balance, the thought goes, the student is actually increasing in perfection (i.e. power). ${ }^{38}$

Given the distinctions between general power, active power, and passive power, there are three readings of the claim a substance increases in power:

Gen-P: A substance increases in general power, that is, the possibility of change. ${ }^{39}$

Act-P: A substance increases in active power, that is, they are effecting

\footnotetext{
${ }^{37}$ For more detailed discussions of the status of power within substances, see Jorati (2019) and Rutherford (2013).

${ }^{38}$ For further discussion of this particular case, and various philosophical problems that arise from Leibniz's account of actvity and passivity, see Kneale (1972).

${ }^{39}$ There are actually two readings of this claim: an increase in the possibility of active power, and an increase in the possibility of passive power.
} 
change in other substances.

Pass-P: A substance increases in passive power, that is, they are being affected by other substances.

Which reading or readings does Leibniz intend? My contention is that pleasure can represent either an increase in general power or an an increase in active power. It cannot represent an increase in passive power. This is because pleasure is supposed to be a perception of perfection, and passive power is not a genuine perfection of a substance. As we will see below, passive power is what causes pain or suffering. In short, when we experience pleasure there are two possible scenarios: the pleasure is either representing an increase in the possibility to effect (active) change or representing an increase in activity.

With this discussion of power in place, let us now turn to the systematic reasons for claiming that pleasure represents an increase in power. It makes sense that pleasure would represent an increase in a substance's power, given Leibniz's views on the relationship between knowledge, power, and pleasure. The basic idea is intuitive and straightforward: when we acquire knowledge, we acquire a metaphysical perfection, and thus we increase in our capacity for action or we become active (Rutherford 1995: 48-9). Consider Discourse $\S 15$ :

Thus a substance... becomes limited in proportion to its more or less perfect manner of expression. This, then, is how one can conceive that substances impede or limit each other, and consequently one can say that, in this sense, they act upon one another and are required, so to speak, to accommodate themselves to one another. For it can happen that a change that increases the expression of one diminishes that of another...Whenever something exercises its efficacy or power [puissance], that is, when it acts [agit], it improves and extends [en mieux et s'étend] itself insofar 
as it acts. Therefore, when a change takes place by which several substances are affected (in fact every change affects all of them), I believe one may say that the substance which immediately passes to a greater degree of perfection [passe à un plus grand degré de perfection] or to a more perfect expression exercises its power [exerce sa puissance] and acts, and the substance which passes to a lesser degree shows its weakness [foiblesse] and is acted upon. I also hold that every action of a substance which has perfection involves some pleasure [volupté], and every passion some pain [douleur] and vice versa. However, it can happen that a present advantage is destroyed by a greater evil in what follows, whence one can sin in acting, that is, in exercising one's power and finding pleasure [plaisir]. (G IV: 440-1/AG: 48; see also Monadology $§ 49-52)^{40}$

Here, I think that Leibniz should be read as claiming that pleasure represents an increase in a substance's active power. Here is how this works. When a substance, $\mathrm{S}_{1}$, acquires knowledge (a metaphysical perfection), $\mathrm{S}_{1}$ increases in active power, and is thus active with respect to some other substance, $\mathrm{S}_{2}$ (who is now passive with respect to $\mathrm{S}_{1}$ ). When $\mathrm{S}_{1}$ is active in this way, $\mathrm{S}_{1}$ experiences pleasure (a further metaphysical perfection). $\mathrm{S}_{2}$, however, is passive and thus will experience pain. ${ }^{41}$

\footnotetext{
${ }^{40}$ In a similar vein, Leibniz writes in the New Essays that "if we take 'action' to be an endeavour towards perfection, and 'passion' to be the opposite, then genuine substances are active only when their perceptions (for I grant perceptions to all of them) are become better developed and more distinct, just as they are passive only when their perceptions are becoming more confused. Consequently, in substances which are capable of pleasure and pain every action is a move toward pleasure, ever passion a move toward pain" (RB: 210).

${ }^{41}$ Strictly speaking, in Discourse $\S 15$ Leibniz claims that "it can happen that a change that increases the expression of one diminishes that of another." This qualification suggests a weaker reading of this passage, whereby it is possible for $S_{1}$ to be active with respect to $S_{2}$, yet $S_{2}$ does not decrease in perfection (it may maintain its degree of perfection or even increase in perfection as well). Whether Leibniz intended this possibility is beyond the scope of this paper. However, the weaker reading is still consistent with the general
} 


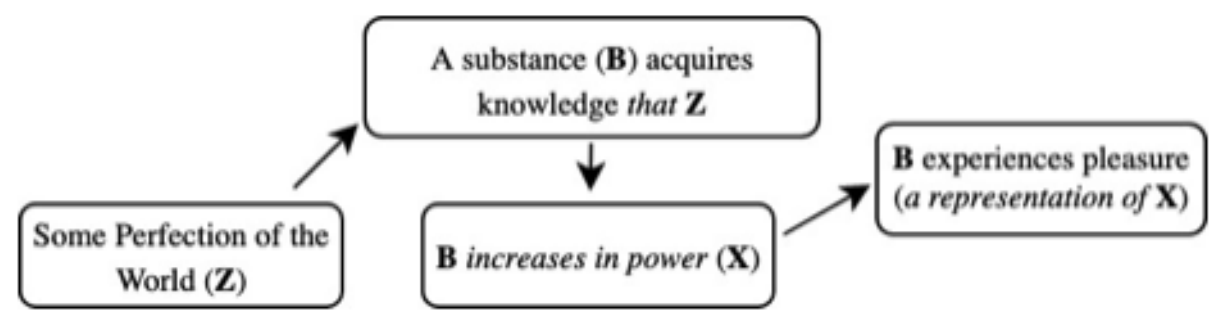

Figure 1: Generation of Pleasure

As Leibniz similarly writes:

The impulse to action arises from a striving toward perfection, the sense of which is pleasure, and there is no action or will on any other basis. (L: 424; emphasis added). ${ }^{42}$

Although Leibniz does not make it explicit that pleasure is a representation of an increase in $\mathrm{S}_{1}$ 's active power, everything he says here (taken together with the prior texts) suggests that this is his considered view.

\section{Leibnizian Happiness}

Reading pleasure as a representation of an increase in a substance's power helps clarify the nature of Leibnizian happiness. First, it offers us a more

interpretation on offer. That is, it still the case that when $\mathrm{S}_{1}$ becomes active and exercises its power, it experiences pleasure (a representation of that increase in power).

${ }^{42}$ Roinila makes a similar observation: "According to Leibniz, activity brings pleasure and passivity brings pain. Joy makes men alert, active and hopeful of further success. However, as the distinctness of perceptions is a matter of degree, activity also comes in degrees. The more distinctly a substance perceives, the more active it is, and at the same time, it is more perfect" (2007: 174). 
precise understanding of the cognitive status of happiness. Second, it helps us understand the metaphysical status of happiness.

\subsection{Happiness as a Mood}

Commentators generally gloss happiness as an enduring or lasting state of pleasure, and Leibniz often characterizes happiness in this way. As such, one might think that happiness consists in an ongoing series of pleasures. However, Leibniz's considered view is more complicated. In Happiness, Leibniz claims that happiness is a lasting state of joy, and that joy consists of the predominance of pleasure over pain.

We have established that pleasure consists in a representation of an increase in a substance's power, whereas pain consists in a representation of a decrease in a substance's power (or an increase in weakness). Thus, let us turn to joy, the predominance of pleasure over pain. Leibniz writes,

Joy is the total pleasure that results from everything the soul feels at once. This is why one can have joy in the midst of great pains, when the pleasures that one feels at the same time are sufficiently great and capable of blotting the pains out: just like in the case of that Spanish slave who, having killed a Carthaginian murdered of his maters, was beside himself with joy, and made light of the torments that the torturers were able to invent. (GR II: 582/SLT: 169)

Here, Leibniz suggests that pleasures can outweigh pains, and when they do, we are in a state of joy. This notion of outweighing does not seem to be merely a quantitative calculation, that is, one is not in a state of joy when there are more experiences of pleasure than experiences of pain at a certain time slice of a rational substance. For this calculation also has qualitative grounds. Pleasure and pain comes in varying degrees. This allows for, say, a singular pleasure about a high degree of perfection (i.e. a significant 
increase in power) to outweigh several experiences of pain that are caused by insignificant decreases in power. In short, we can say that we are in a state of joy when we are more aware of our power than we are aware of our weakness.

Let us now turn to happiness:

Happiness is a lasting state of joy. This is why our joy and our pleasure should not have harmful consequences that cause a much greater or longer lasting sadness or pain. It is in this choice of joys and pleasures and in the means of obtaining them or avoiding sadness that consists the science of happiness [i.e. wisdom]. Some pleasures cause much greater or longer lasting pains, or prevent greater and more enduring pleasures. And there are pains or difficulties that are extremely useful and instructive. Thus it is in their choice, or in the means of obtaining or avoiding them, that consists the science of happiness. (GR II: 582/SLT: 169)

There are two features of this passage that I want to draw out. First, the reason why happiness must be grounded in intellectual pleasure. Second, and relatedly, the cognitive status of happiness, which I claim is a cognitive process (akin to what we would now call a mood-See Haybron [2001]).

Let us start with the first issue. Leibniz stresses that happiness is ultimately grounded in intellectual pleasure as opposed to sensory pleasure, because unlike sensory pleasure, intellectual pleasure is not conducive to future experiences of pain and dips in perfection. Leibniz writes:

The confused perception of some perfection constitutes the pleasure of senses, but this pleasure can be [productive] of greater imperfections, as a fruit with a good taste and a good odor can conceal a poison. This is why one must shun the pleasures of senses, as one shuns a stranger, or, sooner, a flattering enemy. (GR II: 579/R: 83) 
I have bracketed the issue of the nature of sensory pleasure in this paper, primarily because it deserves its own thorough treatment. However, allow me to make a brief remark about how we should understand sensory pleasure, as it will help reveal why Leibniz thinks sensory pleasures are not constitutive of happiness. Sensory pleasure, on the view I prefer, also consists in a representation of perfection. As such, intellectual pleasure and sensory pleasure are unified because they are about the same type of thing. However, the representation in the case of sensory pleasure is not accurate: it is a misrepresentation of perfection. More specifically, a sensory pleasure misrepresents a substance as increasing in power, when in fact, it is increasing in weakness. ${ }^{43}$ For when we engage in bodily activities that are characteristic of producing sensory pleasures we are ultimately being passive and thus suffering. As Leibniz writes:

We act to attain happiness or a state of enduring joy, and joy is the sense of perfection. Every thing is to be held as more perfect to the degree that it is freer by nature; that is, to the degree that its power is greater over the things that surround it, and its suffering from external things is less. (L: 280)

Happiness, on Leibniz's view, needs to be grounded in genuine increases in power. For Leibniz, it is only knowledge of the perfections of God and the universe that can consistently offer us the right kind of increases in power,

\footnotetext{
${ }^{43}$ There is a sense in which, some sensory pleasures are about an increase in power. However, the bases of such sensory pleasures (e.g. dancing, drinking, etc.) are not conducive to genuine increases in power, that is, the kind of power that is stable and conducive to the production of future perfection (i.e. knowledge, happiness, and virtue). It is because sensory pleasures do not represent genuine increases in power which makes them, in reality, misrepresentations of increases in power (i.e. actual representations of increases in weakness). Now, one might object that sensory pleasures are still important to the life of a rational substance. Although Leibniz does not explicitly do this, I would appeal to Descartes' view on this matter. For Descartes, sensory pleasures (and other contingent goods) do not contribute to happiness, but they do contribute to well-being (Svensson 2011). Leibniz surely has the resources to make such a distinction.
} 
and thus the kind of pleasures that are conducive to happiness (H: 282, 297). This is not to say that we should always avoid objects that induce pain. Indeed, there are some cases where we must experience pain in order to experience future pleasure, for there is a significant sense in which acquiring knowledge is a difficult process. Pursuing knowledge is what helps us acquire power (and hence freedom), which in turns puts us in a position to be happy.

This leads to the final point on this first issue: namely, the connection between moral progress (increasing in virtue and happiness) and epistemic progress. Bracketing the issue of virtue, Leibniz is clear that we need to make strong epistemic progress in order to sustain our happiness. Although weak epistemic progress can be a source of pleasure, we cannot-all things considered-become epistemically static:

I doubt that a greatest pleasure is possible; I am inclined to believe that it can increase ad infinitum, for we do not know how far our knowledge and our organs can be developed in the course of the eternity which lies before us. So I would think that happiness is a lasting pleasure, which cannot occur without a continual progress to new pleasures. (RB: 194)

In order for happiness to be sustained, we need to progress to new pleasures. And in order to progress to new pleasures, we need to be consistently acquiring more knowledge of the perfections of the universe and God. Leibniz is implying that if we do not make such strong epistemic progress-"which would dull [stupide] our mind" (G VI: 606/AG: 213)-then we will not be happy.

Let us turn to the second issue concerning happiness. What does it mean for happiness to be a "lasting state of joy"? By lasting, Leibniz does not mean that a happy person is, at every moment of her life, experiencing joy. Indeed, Leibniz claims that "the happy man does not, it is true, feel this joy at every instant" (L: 425, see also L: 280). As such, the view of happiness as an ongoing 
series of pleasures is problematic. In fact, I would argue that Leibniz would say that happiness is not a discrete mental state at all. Rather, happiness is a cognitive process that is akin to a mood. Broadly construed, a mood encompasses the overall emotional state of a subject, allowing for there to be experiences that are not characteristic of the overall mood, e.g. instances of pain (Haybron 2001). As such, happiness is not a particular emotion or set of emotions (e.g. an experience of pleasure or consistent experiences of pleasure). It is possible for the happy person to have experiences of pain and suffering. However, in order to qualify as being happy, their experiences of pleasure must outweigh their experiences of pain (i.e. they must be in a state of joy); and they can ensure this by having their habits and activities geared toward the acquisition of knowledge and the exercise of virtue.

\subsection{Happiness as a Perfection}

Recall, Leibniz claims that happiness is a perfection. For example, he writes in On the Elements of Natural Science (ca. 1682-84) that "happiness consists in the perfection of the mind" (L: 279; see also Discourse §36). Why exactly is happiness a perfection of the mind? Happiness is a mood that represents (net) increases in power. ${ }^{44}$ When we are happy, we are consistently more aware of our power as opposed to our weakness. Given the principle of REPResentational Perfection, it follows straightforwardly that happiness would be a perfection as well. For if happiness (accurately) represents net increases in the perfection of power, then it is, by extension, a perfection of a rational substance as well.

\footnotetext{
${ }^{44}$ I am helping myself to the assumption that cognitive processes and moods can be representational. For recent intentionalist treatments of moods see Kriegel (2019) and Mendelovici (2013).
} 


\section{Conclusion}

Leibniz is a strong intentionalist about pleasure. Although Leibniz is sometimes unclear in his descriptions of the nature of pleasure, claiming that pleasure is both a perception of perfection and caused by a perception of perfection, these claims are not mutually exclusive-Leibniz intends both of them. This is the dual perception of perfection reading I am proposing: pleasure is a representation of an increase in a substance's power, that is caused by knowledge of the perfections of the universe or God. This reveals that Leibniz has a systematic account of pleasure that fits with his metaphysics and epistemology. As Leibniz himself states:

Thus we see that happiness, pleasure, love, perfection, being, power, freedom, harmony, order, and beauty are all tied to each other, a truth which is rightly perceived by few. (L: 426)

I hope to have made some progress towards unpacking these interconnections, but of course, there is much more work to be done. ${ }^{45}$

\section{References}

[1] Adams, R.M. (1994). Leibniz: Determinist, Theist, Idealist. Oxford: Oxford University Press.

[2] Bain, D. (2003). "Intentionalism and Pain." Philosophical Quarterly 53 (213): 502-523.

[3] Bain, D. \& Brady, M. (2014). "Pain, Pleasure, and Unpleasure." Review of Philosophy and Psychology 5(1): 1-14.

\footnotetext{
${ }^{45}$ For feedback and discussion on various drafts of this paper, I would like to thank John Whipple, Alan Nelson, Stephen Puryear, Julia Borcherding, Jun Young Kim, Joseph Gottlieb, and an audience at the 10th International Leibniz Congress. Finally, I would like to thank two anonymous referees of Theoria for their excellent feedback and comments.
} 
[4] Block, N. (1995). "On a Confusion about a Function of Consciousness." Brain and Behavioral Sciences 18(2): 227-247.

[5] Blumenfeld, D. (1995). "Perfection and happiness in the best possible world," In The Cambridge Companion to Leibniz ed. Jolley, N. Cambridge. 382-410.

[6] Bramble, B. (2013). "The Distinctive Feeling Theory of Pleasure." Philosophical Studies 162 (2):201-217.

[7] Brown, G. (1995). "Leibniz's moral philosophy"" In The Cambridge Companion to Leibniz ed. Jolley, N. Cambridge. 411-441.

[8] Brown, G. (2011). "Disinterested Love: Understanding Leibniz's Reconciliation of Self and Other-Regarding Motives." British Journal for the History of Philosophy 19(2): 265-303.

[9] Couturat, L. (1901). La logique de Leibniz: d'après des documents inédits. Paris: Felix Alcan.

[10] Cunning, D. (2006). "Descartes on Sensations and Ideas of Sensations," in in P. Hanna, A. McEvoy and P. Voutsina (eds) An Anthology of Philosophical Studies. Athens: Atiner Publishing. 17-32.

[11] Cutter, B. \& Tye, M. (2011). "Tracking Representationalism and the Painfulness of Pain." Philosophical Issues 21(1):90-109.

[12] De Rosa, R. (2007). "The Myth of Cartesian Qualia." Pacific Philosophical Quarterly 88(2): 181-207.

[13] Duncan, S. (2015). "Leibniz on the Expression of God." Ergo 2(4): 83103.

[14] Field, R. (1993). "Descartes on the Material Falsity of Ideas." The Philosophical Review 102: 309-333.

[15] Frey, J. (2016). "Was Leibniz an Egoist?" Journal for the History of Philosophy 54(4): 601-624.

[16] Garber, D. (2014). "Monads and the Theodicy: Reading Leibniz." In New Essays on Leibniz's Theodicy, edited by Larry M. Jorgensen and Samuel Newlands. Oxford University Press. 218-232. 
[17] Gottlieb, J. \& Parvizian, S. (2018). "Cartesian Imperativism." Pacific Philosophical Quarterly 99(4):702-725.

[18] Grua, G. (1953). Jurisprudence Universelle et Théodicée selon Leibniz. Paris: Press Universitaires de France.

[19] Haybron, D.M. (2001). "Happiness and Pleasure." Philosophy and Phenomenological Research 62 (3):501-528.

[20] Hostler, J. (1975). Leibniz's Moral Philosophy. Harper \& Row.

[21] Irwin, T. (2008). "Leibniz: Naturalism and Eudaemonism," In The Development of Ethics: A Historical and Critical Study Oxford University Press. 312-330.

[22] Johns, C. (2013). The Science of Right in Leibniz's Moral and Political Philosophy. Bloomsbury.

[23] Jorati, J. (2014). "Leibniz's Twofold Gap Between Moral Knowledge and Motivation." British Journal for the History of Philosophy 22(4): 748-766.

[24] Jorati, J. (2018). "Leibniz on Appetitions and Desires," in History of the Philosophy of Mind, Vol. 4: Philosophy of Mind in the Early Modern and Modern Ages, ed. R. Copenhaver. Routledge. 245-65.

[25] Jorati, J. (2019). "Leibniz's Ontology of Force." Oxford Studies in Early Modern Philosophy 8: 189-224.

[26] Jorgensen, L. (2009). "The principle of Continuity and Leibniz's Theory of Consciousness." Journal of the History of Philosophy 47(2): 223-248.

[27] Kriegel, U. (2019). "The Intentional Structure of Moods." Philosopher's Imprint 19: 1-19.

[28] Lee, S. (2014). "Toward a New Reading of Leibnizian Appetites: Appetites as Uneasiness." Res Philosophica 91(1): 123-150.

[29] Leibniz, G.W. (1839). God. Guil. Leibnitii Opera Philosophica ed. Erdmann, J.E. Berlin: Sumtibus G. Eichleri. 
[30] Leibniz, G. W. (1875-90). Die philosophischen Schriften von Gottfried Wilhelm Leibniz. Ed. Gerhardt, C.I. Berlin: Weidman.

[31] Leibniz, G.W. (1860). Briefwechsel zwischen Leibniz und Christian Wolff. Ed. Gerhardt, C.I. Halle repr. Hildesheim: Georg Olms.

[32] Leibniz, G.W. (1885). Rechtphilosophisches aus Leibnizens ungedruckten Schriften. ed. G., Mollat. Leipzig.

[33] Leibniz, G.W. (1923). Sämtliche Schriften und Briefe. Darmstadt and Berlin: Berlin Academy.

[34] Leibniz, G.W. (1948). Textes inédits d'après de la bibliothèque provincial de Hanovre. 2 vols, Ed. Grua, G. Paris: Presses Universitaires.

[35] Leibniz, G.W. (1951). Leibniz Selections. Ed. and trans. Wiener, P.. New York: Charles Scribner's Sons.

[36] Leibniz, G.W. (1969). Philosophical Papers and Letters. Trans. Loemker, L.. Vol. 2. 2nd Ed. Kluwer.

[37] Leibniz, G.W. (1973) Philosophical Writings. Ed. and tr. Morris, M. and Parkinson, G.H.R.. London: Dent.

[38] Leibniz, G.W. (1981). New Essays on Human Understanding. Trans. Remnant, P. and Bennett, J. Cambridge University Press.

[39] Leibniz, G.W. (1985). Theodicy: Essays on the Goodness of God, the Freedom of Man, and the Origin of Evil. Ed. Farrar, A. trans. Huggard, E.M. . La Salle: Open Court.

[40] Leibniz, G.W. (1989). Philosophical Essays Trans. Ariew, R. and Garber, D. Indianapolis: Hackett.

[41] Leibniz, G.W. (2006). The Shorter Leibniz Texts. Trans. Strickland, L. New York: Continuum.

[42] Look, B. C. (2007). "Perfection, Power and the Passions in Spinoza and Leibniz." Revue Roumaine de Philosophie 51 (1), 21-38.

[43] MacKenzie, A. (1990). "Descartes on Sensory Representation." Canadian Journal of Philosophy 20(Supplement): 109-147. 
[44] McRae, R. (1976). Leibniz: Perception, Apperception, and Thought. University of Toronto Press.

[45] McRae, R. (1995). "The Theory of Knowledge," In The Cambridge Companion to Leibniz ed. Jolley, N. Cambridge. 176-198.

[46] Mendelovici, A. (2013). "Pure Intentionalism About Moods and Emotions." In Uriah Kriegel (ed.), Current Controversies in Philosophy of Mind. Routledge. 135-157.

[47] Mercer, C. (2001). Leibniz’ Metaphysics. Its Origins and Development. Cambridge University Press.

[48] Montague, M. (2016). The Given: Experience and its Content. Oxford.

[49] Nelson, A. (2013). "Philosophical Systems and Their History." In Mogens Laerke, Justin Smith, and Eric Schliesser (Eds.), Philosophy and its History. Oxford University Press. 236-257.

[50] Puryear, S. (2012). "Leibniz's Alleged Ambivalence About Sensible Qualities." Studia Leibnitiana 44 (2): 229-245.

[51] Rescher, N. (1967). The Philosophy of Leibniz. Prentice-Hall.

[52] Roinila, M. (2007). Leibniz on Rational Decision-Making. Philosophical Studies from the University of Helsinki 16.

[53] Russell, B. (1937). A Critical Exposition of the Philosophy of Leibniz. 2nd ed. London: George Allen \& Unwin.

[54] Rutherford, D. (1995). Leibniz and the Rational Order of Nature. Cambridge: Cambridge University Press.

[55] Rutherford, D. (2013). "Laws and Powers in Leibniz," in God, Man, and the Order of Nature: Historical Perspectives, ed. Eric Watkins. Oxford. 149-174.

[56] Simmons, A. (1999). "Are Cartesian Sensations Representational?" Noûs 33(3): 347-369.

[57] Simmons, A. (2001). "Changing the Cartesian Mind: Leibniz on Sensation, Representation and Consciousness." The Philosophical Review 110(1): 31-75. 
[58] Strickland, L. (2006). Leibniz Reinterpreted. London: Continuum.

[59] Svensson, F. (2011). "Happiness, Well-Being, and Their Relation to Virtue in Descartes' Ethics". Theoria 77 (3):238-260.

[60] Tye, M. (1995). Ten Problems of Consciousness: A Representational Theory of the Phenomenal Mind. MIT Press.

[61] Tye, M. (2008). "The Experience of Emotion: an Intentionalist Theory." Revue Internationale de Philosophie 62 (1): 25-50.

[62] Whipple, J. (2015). "Leibniz and the Art of Exoteric Writing." Philosophers' Imprint 15(35): 1-24.

[63] Wilson, M. "Confused vs. Distinct Perception in Leibniz: Consciousness, Representation, and God's Mind," In Minds, Ideas, and Objects: Essays on the Theory of Representation in Modern Philosophy ed. Cummins, P. \& Zoeller, G. Ridgeview Publishing Company. 135-150.

[64] Youpa, A (2005). "Rationalist Moral Philosophy", In A Companion to Rationalism. Edited by Nelson, A.. Malden: Blackwell Publishing.

[65] Youpa, Andrew, "Leibniz's Ethics", The Stanford Encyclopedia of Philosophy (Winter 2016 Edition), Edward N. Zalta (ed.), URL = ¡https://plato.stanford.edu/archives/win2016/entries/leibniz-ethics/i. 